\title{
Recurrent Group Analysis in the Classification of Flexibacteria
}

\author{
By E. W. FAGER \\ Scripps Institution of Oceanography, University of California, La Jolla, \\ California 92037 , U.S.A.
}

(Accepted for publication 4 June I969)

\section{SUMMARY}

A computer programme was used to group 85 strains of flexibacteria on the basis of similarity in 84 structural, physiological and biochemical characteristics. The procedure gave 19 groups, the members of which were very similar in their characteristics. The groups could be grouped in seven assemblages whose members showed lesser, but still considerable, similarity. The groups may represent taxonomic entities at the species level; the assemblages, those at the generic level.

A computer programme originally developed for identifying communities by determining recurrent groups of invertebrates* on the basis of their frequency of cooccurrence in samples of forest litter, soil, and zoo-plankton (Fager, 1957; Fager \& McGowan, 1963) was used, with little change, for grouping the strains of flexibacteria investigated by Lewin \& Lounsbery (1969). For each pair of strains, the programme calculated an index of affinity, the geometric mean of the proportion of common characteristics corrected for the number of characteristics recorded for the strains $(J / \sqrt{ }(A \times B)-1 / 2 \sqrt{ } B$; where $A$ and $B$ are the total numbers of characteristics recorded for the two strains, $B \geqslant A$, and $J$ is the number of common characteristics, i.e. positive matches). All characteristics were weighted equally. Unlike most grouping procedures (Sneath, I962), the programme first formed the largest group within which all possible pairs of strains had affinity indices at or above a preset value. The members of the first group were then removed from further consideration and the largest possible group was formed among the remaining strains. This process was continued until all strains were either placed in a group or designated associates of a group. The latter were strains that had affinity indices above the preset level with some, but not all, of the members of a group. Where two or more groups of the same size were possible, the programme selected the one for which the sum of affinity indices for all pairs of species within the group was greatest. When the alternative groups had species in common, this resulted in elimination of one or more groups. When there were no species in common, all groups were eventually selected. It has been found in previous work that values of the index in the range 0.500 to 0.600 give useful groupings. In the present case, the use of 0.575 gave a number of groups of reasonable size without involving very large numbers of alternative groups that would require excessive computer time.

The 84 structural, physiological and biochemical characteristics that were recorded for the strains are given in Table I. Information on the metabolism of various carbo-

* FORTRAN listings are available for the grouping programme (REGROUP), the programme for determining connections between groups (CONNEX), and the programme for listing the characteristics shared by group members (STATION). These have been programmed for the CDC 3600 . 
Table I. Characteristics recorded, based on the data of Lewin \& Lounsberg (1969).

Guanine+cytosine mole \% in DNA

Less than $30 \%$

$30 \cdot 0$ to $32 \cdot 5$

32.6 to $35^{\circ} 0$

$35 \cdot 1$ to $37 \cdot 5$

$37 \cdot 6$ to $40 \cdot 0$

Less than $10 \mu$ in length Io to $50 \mu$ in length Greater than $50 \mu$ in length Helical

Type I-red (flexixanthin)

Type III-orange (saproxanthin)
Type II-pink

$40 \cdot I$ to $42 \cdot 5$

$42 \cdot 6$ to $45^{\circ} 0$

$45 \cdot I$ to $47 \cdot 5$

$47 \cdot 6$ to $50 \cdot 0$

Greater than 50.0

Morphology, etc.

Not helical

Rhapidosomes observed

Rhapidosomes not observed

Sheathed

Pigmentation

Type IV-yellow (zeaxanthin)

Type V-yellow

Type VI-red

Digestive enzymes

Liquefies carboxymethylcellulose

Does not liquefy carboxymethylcellulose

Hydrolyses starch

Does not hydrolyse starch

Liquefies gelatin

Does not liquefy gelatin

Liquefies agar

Does not liquefy agar

Liquefies alginate

Does not liquefy alginate

Oxidation-reduction enzymes

Catalase produced

Catalase not produced

$\mathrm{H}_{2} \mathrm{~S}$ evolved

$\mathrm{H}_{2} \mathrm{~S}$ not evolved

Reactions to tyrosine ( $5 \mathrm{~g} . / 1$.) and dihydroxyphenylalanine (0.1 g./1.)

No growth on tyrosine

Growth, plus colour change

Growth, no colour change

Growth, plus dissolution

Growth, no dissolution
No growth on dihydroxyphenylalanine

Growth, plus colour change

Growth, no colour change

Growth, plus dissolution

Growth, no dissolution

Effect of inhibitors

Not inhibited by penicillin $\left(\mathrm{IO}^{-6} \mathrm{~g} . / 1\right.$.)

Inhibited by penicillin $\left(10^{-6} \mathrm{~g}\right.$. $/ \mathrm{l}$.)

Not inhibited by lauryl sulphate (0.I g./1.)

Inhibited by lauryl sulphate (0.1 g./1.)

Vitamin requirements

Thiamine required

Thiamine not required

Cobalamin not required

Other vitamins not required

Cobalamin required

Temperature effects

Can grow above $40^{\circ}$

Can grow above $35^{\circ}$ but not $40^{\circ}$

Can grow above $30^{\circ}$ but not $35^{\circ}$

Salinity tolerances

Can grow in above $2 \times$ sea-water media

Can grow in sea water but not $2 \times$ sea-water media

Can grow in $\frac{1}{2} \times$ sea water but not sea-water media
Cannot grow in diluted sea-water media

Can grow in diluted sea water but not freshwater media

Can grow in freshwater media 
Table I (cont.)

Nitrogen requirements

Nitrate alone suffices

Glutamate alone suffices, but not nitrate

Arginine required

Aspartic acid required

Histidine required

Glycine required

Isoleucine required

Leucine required

Lysine required

Methionine required
Phenylalanine or tyrosine required

Threonine required

Tryptophan required

Valine required

Asparagine required

Growth on Casamino acids alone (specific requirements unknown)

Growth on Casamino acids plus yeast nucleic acid hydrolysate

Growth on Tryptone but not on Casamino acids

hydrates was also available, but it was decided that the data were too imprecise to use ( $c f$. Dworkin, I966) and they were, therefore, omitted. Details of experimental procedures will be found in Lewin \& Lounsbery (1969). The strain designations used in this paper are the ones used by those authors.

Eighty-five strains of flexibacteria were used. Some strains had positive scores for as many as 33 characteristics, others for as few as I4. The different numbers are the result of two things: incomplete information about some strains and an attempt to minimize the amount of redundant information used. As an example of the latter, a strain that could use nitrate as sole nitrogen source was not scored as not requiring any of the 13 amino acids tested and was, therefore, recorded only once in regard to the nitrogen requirements, whereas a strain that required specific amino acids could be recorded up to 13 times. These differences may have had some effect on the groupings but every species had enough positive scores to have had affinity (at 0.575 ) with any of the others.

The grouping procedure gave I9 groups, varying in size from I to 19 members. The two single-member groups were strains that showed no affinities with any other strains. Nine strains were close associates but not members of groups. In some cases, their exclusion may have been due to lack of information about these strains.

The groups and associates and their interrelations are shown in Fig. I. The interrelations are based on determination of the number of pairs of strains that showed affinity between two groups and comparison of this with the possible number. For example, if one group consisted of four strains and another of five, there would be 20 possible between-group pairs of strains and, of these, any number from o to I $9 \mathrm{might}$ show affinity at or above the preset level. If 20 between-group pairs had shown affinity, the grouping procedure would have put the two groups together in one. As Fig I. indicates, the groups can be grouped in 7 separate assemblages: groups I, I 2, 18 and 19 by themselves and the rest in three more or less closely connected assemblages of groups. (These assemblages have been designated FA through FG.)

The individual groups are based on similarity of characteristics of their component members and may represent taxonomic entities at the species level. After the groups were determined, the common characteristics of the members of each group were listed. These are shown in Table 2.

The assemblages, based on appreciable but lesser similarity between the groups, may represent taxa at the generic level. For example, in assemblage FC, group 7 consisted of strains that had guanine + cytosine values between 32.5 and $35.0 \%$, were not helical, were yellow, liquefied gelatin, carboxymethylcellulose, agar and alginate, 
Table 2. Characteristics shared by members of recurrent groups of strains

Group I

Helical

Rhapidosomes observed

Pigment type III-orange (saproxanthin)

Does not hydrolyse starch

Liquefies gelatin

Does not liquefy agar

Catalase not produced

$\mathrm{H}_{2} \mathrm{~S}$ not evolved

Growth, no dissolution of tyrosine $(5 \mathrm{~g} . / 1$.)

No growth on dihydroxyphenylalanine (0.I g./l.)

Inhibited by lauryl sulphate (0.1 g./1.)

Not helical

Pigment type III-orange (saproxanthin)

Liquefies carboxymethylcellulose

Hydrolyses starch

Liquefies alginate

Catalase not produced

Not helical

Pigment type IV-yellow (zeaxanthin)

Does not hydrolyse starch

Does not liquefy agar

Does not liquefy alginate

Catalase not produced

$\mathrm{H}_{2} \mathrm{~S}$ not evolved

Growth, no colour change on tyrosine ( $5 \mathrm{~g} . / 1$.)
Arginine required

Aspartic acid required

Histidine required

Iso-leucine required

Leucine required

Lysine required

Methionine required

Phenylalanine or tyrosine required

Threonine required

Tryptophan required

Valine required

Asparagine required

\section{Group 2}

$\mathrm{H}_{2} \mathrm{~S}$ evolved

Growth, no colour change on tyrosine ( $5 \mathrm{~g} . / 1$.)

Growth, no dissolution of tyrosine $(5 \mathrm{~g} . / 1$.)

Can grow in above $2 \times$ sea-water media

Can grow in diluted sea water but not freshwater media

\section{Group 3}

Growth, no dissolution of tyrosine ( $5 \mathrm{~g}$. $/ \mathrm{l}$.)

Growth, no colour change on dihydroxyphenylalanine $(0 \cdot 1 \mathrm{~g} . / 1$.

Inhibited by lauryl sulphate $(0 \cdot 1 \mathrm{~g} . / 1$.)

Can grow in above $2 \times$ sea-water media

Can grow in diluted sea water but not freshwater media

\section{Group 4}

Greater than $50 \mu \mathrm{m}$. in length

Not helical

Rhapidosomes not observed

Does not liquefy carboxymethylcellulose

Liquefies gelatin

Does not liquefy agar

Does not liquefy alginate

Catalase not produced

No growth on tyrosine ( $5 \mathrm{~g} . / 1$.)

No growth on dihydroxyphenylalanine (0.I g./l.)

Inhibited by lauryl sulphate (0. I g./1.)

Thiamine required

Other vitamins not required

Can grow in freshwater media

Isoleucine required

Leucine required

Methionine required

Phenylalanine or tyrosine required

Valine required

\section{Group 5}

Not helical

Does not liquefy agar

Does not liquefy alginate

Catalase not produced

Growth, no colour change on tyrosine ( $5 \mathrm{~g} . / \mathrm{l}$.)

Growth, no dissolution of tyrosine ( $5 \mathrm{~g} . / \mathrm{l}$.)

Growth, no dissolution of dihydroxyphenylalanine ( $0.1 \mathrm{~g} . / 1$.)

Inhibited by lauryl sulphate $(0 \cdot$ I g./1.)

Can grow in above $2 \times$ sea-water media

Group 6

Io to $50 \mu \mathrm{m}$. in length

Not helical

Rhapidosomes not observed

Pigment type III-orange (saproxanthin)
Does not liquefy carboxymethyl cellulose

Liquefies gelatin

Does not liquefy agar

Does not liquefy alginate 


\section{Table 2 (cont.)}

\section{Group 6 cont.}

Catalase not produced

$\mathrm{H}_{2} \mathrm{~S}$ evolved

Growth, no colour change on tyrosine ( 5 g./1.)

Growth, no dissolution of tyrosine ( $5 \mathrm{~g} . / 1$.

No growth on dihydroxyphenylalanine $(0 \cdot 1 \mathrm{~g} . / 1$.)

Inhibited by lauryl sulphate (O.I g./1.)
Cobalamin not required

Can grow in freshwater media

Isoleucine required

Leucine required

Methionine required

Valine required

\section{Group 7}

Guanine + cytosine mole \% in DNA, 32.5 to $35^{\circ} \mathrm{O}$

Not helical

Pigment type IV-yellow (zeaxanthin)

Liquefies carboxymethylcellulose

Hydrolyses starch

Liquefies agar

Liquefies alginate

Catalase produced

Growth, plus colour change on tyrosine ( $5 \mathrm{~g} . / 1$.)
Growth, plus dissolution of tyrosine ( $5 \mathrm{~g} . / 1$.)

Inhibited by lauryl sulphate ( $0 \cdot 1 \mathrm{~g} . / 1$.)

Thiamine not required

Cobalamin not required

Other vitamins not required

Can grow in above $2 \times$ sea-water media

Can grow in diluted sea water but not freshwater media

Glutamate, but not nitrate, suffices as nitrogen source

\section{Group 8}

Io to $50 \mu \mathrm{m}$. in length

Not helical

Rhapidosomes not observed

Liquefies carboxymethylcellulose

Liquefies gelatin

Does not liquefy agar

Does not liquefy alginate

Catalase not produced

Greater than $50 \mu \mathrm{m}$. in length

Helical

Rhapidosomes not observed

Pigment type II-pink

Does not liquefy carboxymethylcellulose

Hydrolyses starch

Liquefies gelatin

Does not liquefy agar

Does not liquefy alginate

Catalase not produced

$\mathrm{H}_{2} \mathrm{~S}$ evolved

Growth, no colour change on tyrosine ( 5 g./1.)
Inhibited by lauryl sulphate (0.I g./1.)

Thiamine not required

Cobalamin not required

Can grow above $35^{\circ}$ but not $40^{\circ}$

Can grow in $\frac{1}{2} \times$ sea water but not sea-water media

Can grow in freshwater media

Nitrate alone suffices as nitrogen source

\section{Group 9}

Growth, no dissolution of tyrosine ( $5 \mathrm{~g} . / 1$.)

Inhibited by lauryl sulphate $(0 \cdot 1 \mathrm{~g} . / 1$. $)$

Cobalamin required

Can grow above $40^{\circ}$

Can grow in $\frac{1}{2} \times$ sea water but not sea-water media

Can grow in freshwater media

Aspartic acid required

Isoleucine required

Leucine required

Phenylalanine or tyrosine required

Valine required

Group Io

Guanine + cytosine mole $\%$ in DNA, 30.0 to $32 \cdot 5$

Io to $50 \mu \mathrm{m}$. in length

Not helical

Rhapidosomes not observed

Pigment type V-yellow

Liquefies carboxymethylcellulose

Liquefies gelatin

Does not liquefy agar

Does not liquefy alginate

Catalase produced

$\mathrm{H}_{2} \mathrm{~S}$ not evolved

Growth, no colour change on tyrosine ( $5 \mathrm{~g} . / 1$.)
Growth, plus dissolution of tyrosine ( $5 \mathrm{~g} . / 1$.)

Growth, no colour change on dihydroxyphenylalanine $(0 \cdot$ I g./l.)

Growth, no dissolution on dihydroxyphenylalanine ( 0.1 g./l.)

Not inhibited by penicillin $\left(10^{-6} \mathrm{~g}\right.$./l.)

Not inhibited by lauryl sulphate (0.I g./l.)

Thiamine not required

Cobalamin not required

Other vitamins not required

Can grow above $30^{\circ}$ but not $35^{\circ}$

Can grow in freshwater media

Nitrate alone suffices as nitrogen source 
Table 2 (cont.)

Group I I

Greater than $50 \mu \mathrm{m}$. in length

Not helical

Sheathed

Pigment type III-orange (saproxanthin)

Does not liquefy carboxymethylcellulose

Does not hydrolyse starch

Does not liquefy agar

Does not liquefy alginate

Catalase not produced

$\mathrm{H}_{2} \mathrm{~S}$ not evolved

Growth, no colour change on tyrosine ( $5 \mathrm{~g} . / 1$.)
Growth, no dissolution on tyrosine ( $5 \mathrm{~g} . / \mathrm{l}$.)

Growth, no colour change on dihydroxyphenylalanine (o. I g./l.)

Growth, no dissolution on dihydroxyphenylalanine (O.I g. $/ 1$.)

Inhibited by lauryl sulphate ( $0 \cdot 1 \mathrm{~g} . / 1$.)

Can grow above $30^{\circ}$ but not $35^{\circ}$

Can grow in above $2 \times$ sea-water media

Can grow in diluted sea water but not freshwater media

\section{Group 12}

Guanine + cytosine mole \% in DNA, 37.6 to 40.0

Not helical

Pigment type III-orange (saproxanthin)

Does not liquefy carboxymethylcellulose

Hydrolyses starch

Does not liquefy gelatin

Does not liquefy agar

Liquefies alginate

Catalase not produced

$\mathrm{H}_{2} \mathrm{~S}$ not evolved
Growth, no colour change on dihydroxyphenylalanine ( $0 . \mathrm{I}$ g. $/ 1$.)

Growth, no dissolution on dihydroxyphenylalanine (0.1 g./1.)

Inhibited by lauryl sulphate ( $0.1 \mathrm{~g} . / 1$.)

Can grow above $30^{\circ}$ but not $35^{\circ}$

Can grow in above $2 \times$ sea-water media

Can grow in diluted sea water but not freshwater media

Growth on Tryptone but not on Casamino acids

Group I 3

Guanine+cytosine mole $\%$ in DNA, $35 \cdot 1$ to

Does not liquefy agar $37 \cdot 5$

Io to $50 \mu \mathrm{m}$. in length

Not helical

Pigment type III-orange (saproxanthin)

Does not liquefy carboxymethylcellulose

Hydrolyses starch

Liquefies gelatin

Does not liquefy alginate

Catalase not produced

$\mathrm{H}_{2} \mathrm{~S}$ evolved

Growth, no colour change on tyrosine ( $5 \mathrm{~g} . / 1$.)

Growth, no dissolution on tyrosine $(5 \mathrm{~g}$. $/ 1$.)

Inhibited by lauryl sulphate (0.1 g./l.)

Can grow in above $2 \times$ sea-water media

\section{Group 14}

Guanine + cytosine mole $\%$ in DNA $40 \cdot 1$ to

$\mathrm{H}_{2} \mathrm{~S}$ not evolved $42 \cdot 5$

Not helical

Pigment type III-orange (saproxanthin)

Liquefies carboxymethylcelullose

Hydrolyses starch

Liquefies gelatin

Liquefies agar

Liquefies alginate

Catalase not produced

Io to $50 \mu \mathrm{m}$. in length

Not helical

Rhapidosomes observed

Liquefies carboxymethylcellulose

Hydrolyses starch

Liquefies gelatin

Liquefies agar

Liquefies alginate

$\mathrm{H}_{2} \mathrm{~S}$ evolved

Growth, no dissolution on tyrosine ( $5 \mathrm{~g} . / 1$.)

Growth, no colour change on tyrosine ( $5 \mathrm{~g}$./l.)

Growth, no dissolution on tyrosine ( $5 \mathrm{~g} . / \mathrm{l}$.)

Not inhibited by penicillin ( $\mathrm{IO}^{-6} \mathrm{~g} . / 1$.)

Inhibited by lauryl sulphate $(0.1 \mathrm{~g} . / 1$.)

Can grow above $30^{\circ}$ but not $35^{\circ}$

Can grow in above $2 \times$ sea-water media

Can grow in diluted sea water but not freshwater media

\section{Group 15}

Not inhibited by penicillin $\left(10^{-6} \mathrm{~g} . / 1\right.$.)

Thiamine not required

Cobalamin not required

Other vitamins not required

Can grow above $35^{\circ}$ but not $40^{\circ}$

Can grow in above $2 \times$ sea-water media

Can grow in diluted sea water but not freshwater media

Glutamate, but not nitrate suffices as nitrogen source 


\title{
Table 2 (cont.)
}

Group I6

Guanine + cytosine mole $\%$ in DNA, 32.6 to $35^{\circ} 0$

Less than 1o $\mu \mathrm{m}$. in length

Not helical

Rhapidosomes not observed

Pigment type IV-yellow (zeaxanthin)

Does not liquefy carboxymethylcellulose

Liquefies gelatin

Does not liquefy agar
Does not liquefy alginate

Catalase not produced

$\mathrm{H}_{2} \mathrm{~S}$ not evolved

Growth, plus dissolution on tyrosine $(5 \mathrm{~g} . / 1$.)

No growth on dihydroxyphenylalanine $(0 \cdot \mathrm{I}$ g./l.)

Inhibited by lauryl sulphate ( $0.1 \mathrm{~g} . / \mathrm{l}$.)

Thiamine not required

Cobalamin not required

Other vitamins not required

Group I7

Not helical

Rhapidosomes not observed

Pigment type III-orange (saproxanthin)

Does not liquefy carboxymethylcellulose

Does not hydrolyse starch

Liquefies gelatin

Does not liquefy agar

Doos not liquefy alginate

Catalase not produced

$\mathrm{H}_{2} \mathrm{~S}$ not evolved

Growth, no colour change on tyrosine ( $5 \mathrm{~g} . / \mathrm{l}$.)

Growth, no dissolution on tyrosine $(5 \mathrm{~g} . / \mathrm{l}$.)

Inhibited by lauryl sulphate ( $0 \cdot 1$ g./l.)

Can grow in freshwater media

\section{Group I8}

Guanine + cytosine mole \% in DNA, 40.1 to

Growth, no colour change on tyrosine ( $5 \mathrm{~g} . / 1$ ) $42 \cdot 5$

Greater than $50 \mu \mathrm{m}$. in length

Not helical

Rhapidosomes observed

Pigment type III-orange (saproxanthin)

Does not liquefy carboxymethylcellulose

Liquefies gelatin

Does not liquefy agar

Does not liquefy alginate

Catalase not produced

Growth, plus dissolution on tyrosine ( $5 \mathrm{~g}$./1.)

No growth on dihydroxyphenylalanine

(o. I g./1.)

Not inhibited by penicillin $\left(10^{-6} \mathrm{~g} . / 1\right.$.)

Inhibited by lauryl sulphate ( $0.1 \mathrm{~g} . / 1$.)

Can grow above $30^{\circ}$ but not $35^{\circ}$

Can grow in above $2 \times$ sea-water media

Cannot grow in diluted sea-water media

Growth on Tryptone but not on Casamino acids

\section{Group 19}

Guanine + cytosine percentage in DNA, $42 \cdot 6$ to 45.0

1o to $50 \mu \mathrm{m}$. in length

Not helical

Rhapidosomes observed

Sheathed

Pigment type III-orange (saproxanthin)

Liquefies agar

\author{
Liquefies alginate \\ Inhibited by lauryl sulphate ( $0 \cdot$ I g./l.) \\ Thiamine not required \\ Cobalamin not required \\ Other vitamins not required \\ Glutamate, but not nitrate, suffices as nitrogen \\ source
}

hydrolysed starch, grew on tyrosine medium with colour change and dissolution, could use glutamate but not nitrate as nitrogen source, and grew in $2 \times$ to $\frac{1}{2} \times$ sea-water media. Group 15 was made up of strains with much the same characteristics except that it contained both orange and yellow strains, had guanine + cytosine values between 32.5 and $37.5 \%$, and growth on tyrosine medium did not result in dissolution and was variable in colour change. The strains in group 14 were similar to those in group 15 but had guanine + cytosine values between 40 and $42.5 \%$, were both orange, and did not produce a colour change on tyrosine medium; no information was available on their nitrogen requirements. Group 2 consisted of strains much like those in group 14 except that they had guanine + cytosine values ranging from 30 to 
FA

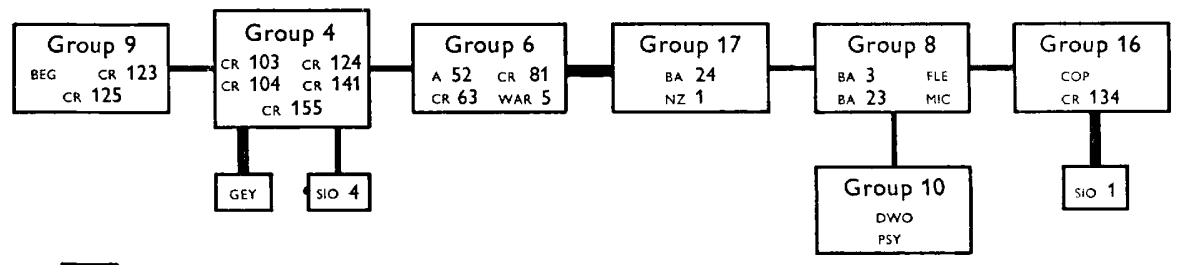

FB

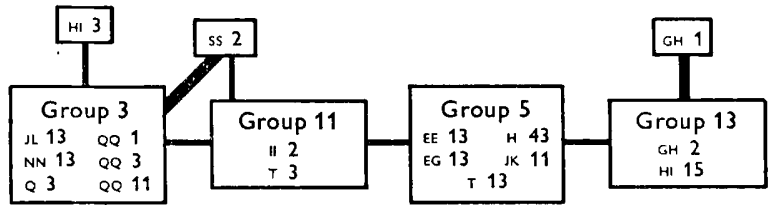

FC

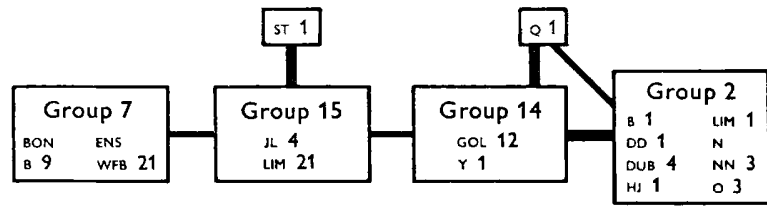

FD

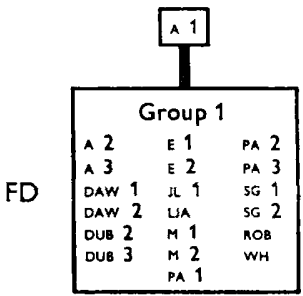

FE

\begin{tabular}{|c|}
\hline Group 12 \\
sol 7 \\
sio 9 \\
\hline
\end{tabular}

FF

Group 18
Sio 8

FG

Group 19

Fig. I. Groups and interrelations of groups among 85 strains of flexibacteria, as defined by a computer programme for determination of recurrent groups. The groups are numbered I through 19. Associates are shown in the small boxes connected to the groups. Assemblages of groups are designated FA through FG. Heavier lines $=\frac{1}{2}$ or more of the possible connections between groups realized; lighter lines = between $\frac{1}{4}$ and $\frac{1}{2}$ of the possible connections realized (see text).

$45 \%$, and one strain (HJ I) which did not liquefy agar or gelatin. The groups in this assemblage (FC) have, therefore, considerable similarity.

The arrangement of the strains in groups and of the groups in assemblages is based on overall similarities using all of the information available. All of the characters were given equal weight. As Sneath (1962) pointed out, this procedure leads to a consistent taxonomy, and is particularly useful when the aim is to form taxa of greatest information content. Although the groups and assemblages suggested by the computer analysis have been used for the most part by Lewin (1969) as a basis for classification, he has in some cases departed from them because he felt that certain characteristics should be given more weight than others in defining species and genera. A detailed discussion of his reasons for the changes is given in his paper. 


\section{REFERENCES}

Dworkin, M. (I966). Biology of the myxobacteria. A. Rev. Microbiol. 20, 75.

FAGER, E. W. (1957). Determination and analysis of recurrent groups. Ecology 38, 586.

FAGER, E. W. \& McGowaN, J. A. (1963). Zoo-plankton species groups in the North Pacific. Science, N.Y. 140, 453.

LewIN, R. A. (1969). A classification of flexibacteria. J. gen. Microbiol. 58, 189.

LEWIN, R. A. \& LoUNSBERY, D. M. (1969). Isolation, cultivation and characterization of flexibacteria. J. gen. Microbiol. 58, I45.

SNeATh, P. H. A. (1962). The construction of taxonomic groups. Symp. Soc. gen. Microbiol. 12, 289. 